\title{
Author Correction: Neural and sociocultural mediators of ethnic differences in pain
}

Elizabeth A. Reynolds Losin (D, Choong-Wan Woo (1D, Natalia A. Medina, Jessica R. Andrews-Hanna, Hedwig Eisenbarth (1D) and Tor D. Wager (D)

Correction to: Nature Human Behaviour https://doi.org/10.1038/s41562-020-0819-8, published online 3 February 2020.

In the version of this article initially published, in Figs. $3 \mathrm{a}$ and 5 a the labels on the brain slices labelled NAc should read ' $y=5$ ' instead of ' $y=-12$ ', and in Fig. 3a the label ' $x=45$ ' on the top brain slice labeled $\mathrm{mFG}$ was missing. The errors have been corrected in the HTML and PDF versions of the article. 
a

Regions where AA are more responsive to painful heat
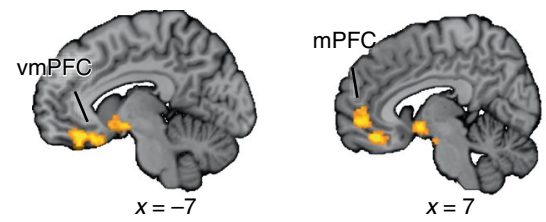

Region activity to painful heat across groups
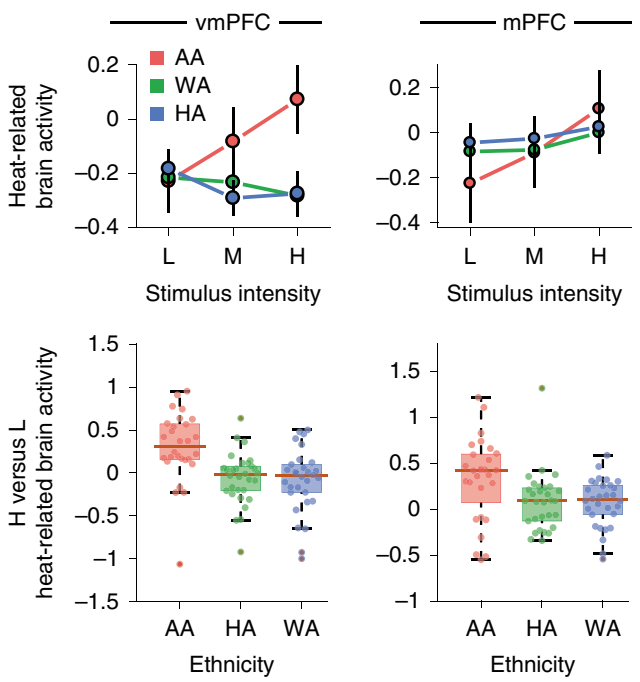

a

Regions where AA are more responsive to painful heat
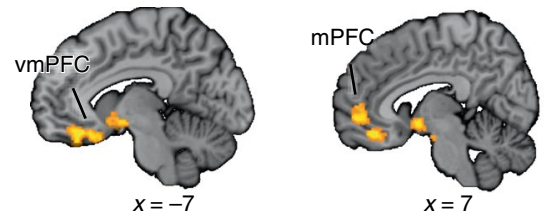

b

Region activity to painful heat across groups
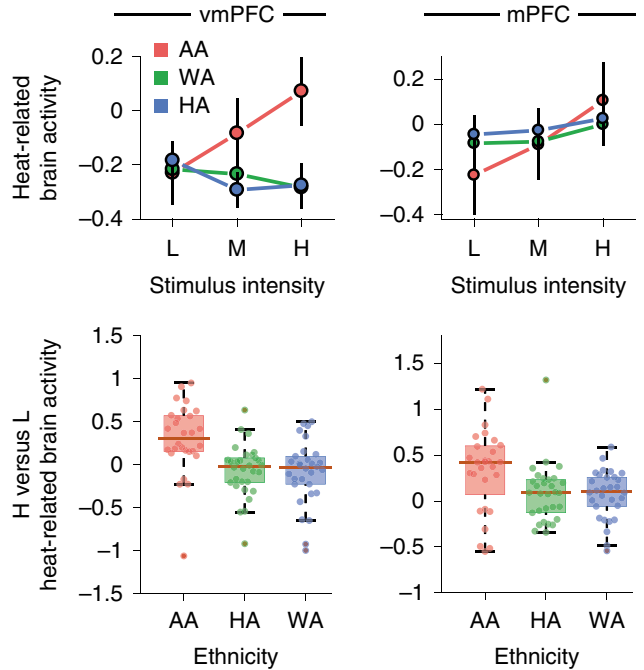

Original
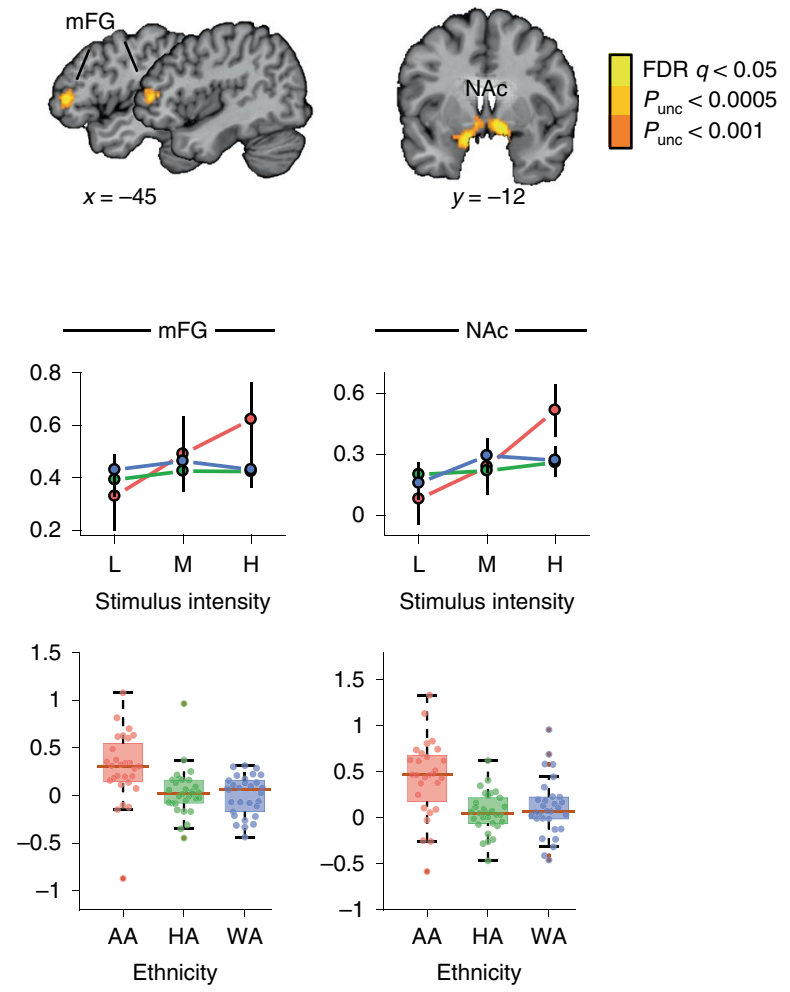

\section{Corrected}
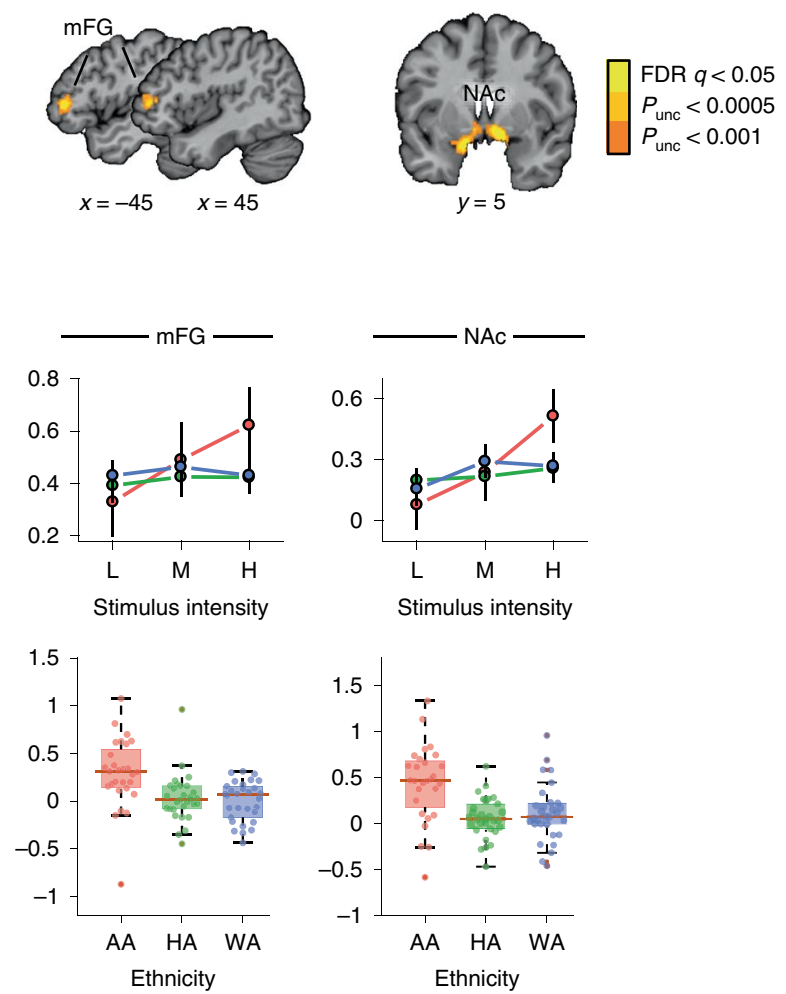

Fig. $\mathbf{3}$ | Original and Corrected. 


Fig. 5 / Original and Corrected.
Published online: 3 March 2020
https://doi.org/10.1038/s41562-020-0838-5
$\odot$ The Author(s), under exclusive licence to Springer Nature Limited 2020
$P_{\text {unc }}<0.001$

